Provided for non-commercial research and education use. Not for reproduction, distribution or commercial use.

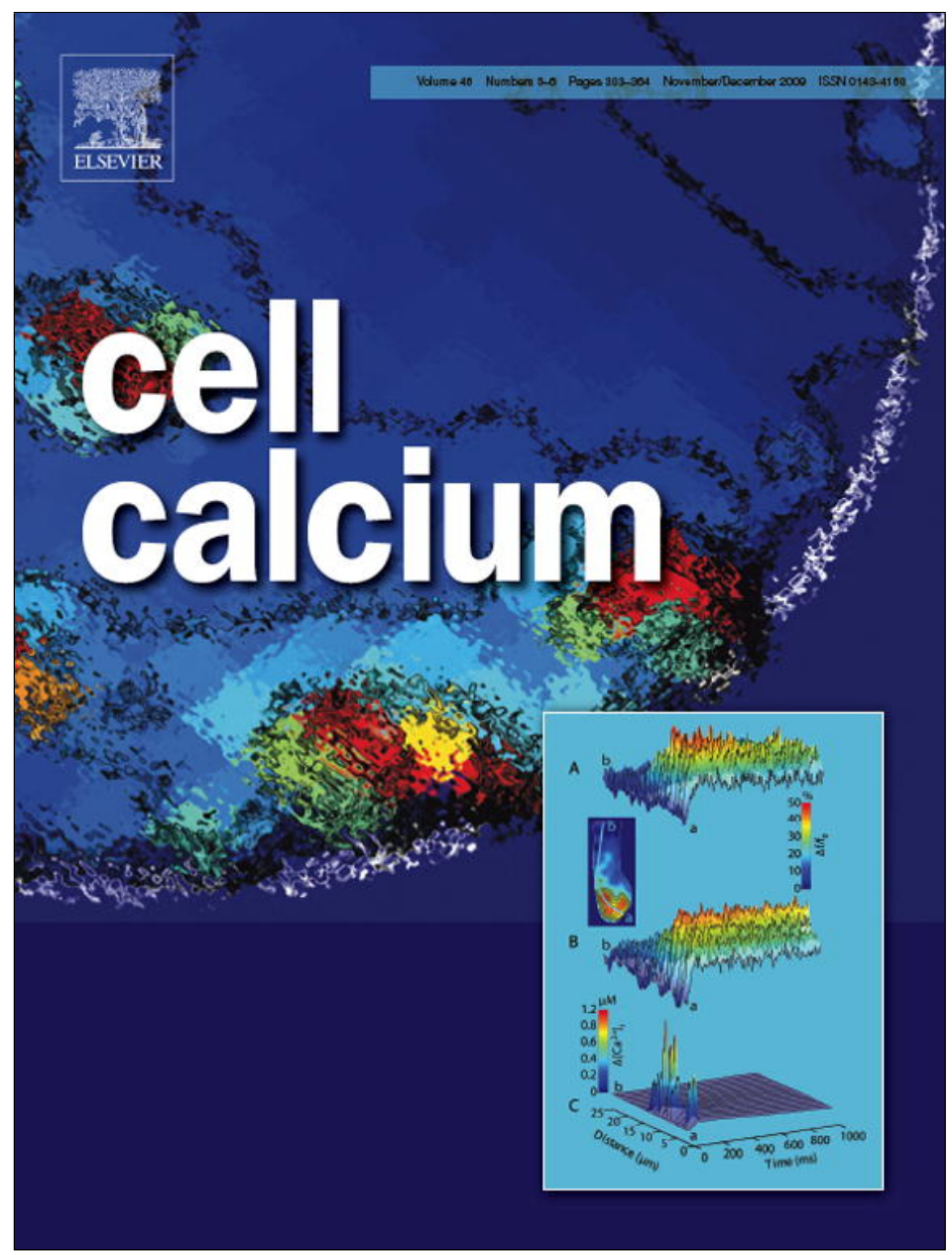

This article appeared in a journal published by Elsevier. The attached copy is furnished to the author for internal non-commercial research and education use, including for instruction at the authors institution and sharing with colleagues.

Other uses, including reproduction and distribution, or selling or licensing copies, or posting to personal, institutional or third party websites are prohibited.

In most cases authors are permitted to post their version of the article (e.g. in Word or Tex form) to their personal website or institutional repository. Authors requiring further information regarding Elsevier's archiving and manuscript policies are encouraged to visit:

http://www.elsevier.com/copyright 


\title{
L-type channel inhibition by CB1 cannabinoid receptors is mediated by PTX-sensitive G proteins and cAMP/PKA in GT1-7 hypothalamic neurons
}

\author{
Hanaa Hoddah ${ }^{\mathrm{b}, 1}$, Andrea Marcantoni ${ }^{\mathrm{a}, 1}$, Valentina Comunanza ${ }^{\mathrm{a}}$, Valentina Carabelli ${ }^{\mathrm{a}}$, Emilio Carbone ${ }^{\mathrm{a}, *}$ \\ a Department of Neuroscience, NIS Center, CNISM Research Unit, Corso Raffaello 30, 10125 Torino, Italy \\ ${ }^{\mathrm{b}}$ Department of Biology, University Abdelmalek Essaadi, Tetouan, Morocco
}

\section{A R T I C L E I N F O}

Article history:

Received 8 August 2009

Accepted 31 August 2009

Available online 8 October 2009

\section{Keywords:}

Cannabinoids

Voltage-gated calcium channels

CB1 inverse agonists

cAMP/PKA signal pathway

Immortalized GnRH neurons

\begin{abstract}
A B S T R A C T
Using immortalized hypothalamic GT1-7 neurons, which express the CB1 cannabinoid receptor (CB1R) and three $\mathrm{Ca}^{2+}$ channel types (T, R and L), we found that the CB1R agonist WIN 55,212-2 inhibited the voltage-gated $\mathrm{Ca}^{2+}$ currents by about 35\%. The inhibition by WIN 55,212-2 (10 $\left.\mu \mathrm{M}\right)$ was reversible and prevented by nifedipine ( $3 \mu \mathrm{M})$, suggesting a selective action on L-type $\mathrm{Ca}^{2+}$ channels (LTCCs). WIN 55,212-2 action exhibited all the features of voltage-independent $\mathrm{Ca}^{2+}$ channel modulation: (1) no changes of the activation kinetics, (2) equal depressive action at all potentials and (3) no facilitation following strong prepulses. At variance with WIN 55,212-2, the CB1R inverse agonist AM-251 (10 $\mu \mathrm{M})$ caused $20 \%$ increase of $\mathrm{Ca}^{2+}$ currents. The inhibition of LTCCs by WIN 55,212-2 was prevented by overnight PTX-incubation and by intracellular perfusion with GDP- $\beta$-S. The latter caused also a $20 \% \mathrm{Ca}^{2+}$ current up-regulation. WIN 55,212-2 action was also prevented by application of the PKA-blocker H89 or by loading the neurons with 8-CPT-CAMP. Our results suggest that LTCCs in GT1-7 neurons are partially inhibited at rest due to a constitutive CB1R activity removed by AM-251 and GDP- $\beta$-S. Activation of CB1R via PTX-sensitive $G$ proteins and CAMP/PKA pathway selectively depresses LTCCs that critically control the synchronized spontaneous firing and pulsatile release of gonadotropin-releasing hormone in GT1-7 neurons.
\end{abstract}

(c) 2009 Elsevier Ltd. All rights reserved.

\section{Introduction}

Cannabinoids are the primary psychoactive constituents of marijuana that have profound effects on pain perception, neural convulsions, memory and motor coordination $[1,2]$. Their effects are most commonly mediated by the $\mathrm{CB} 1$ cannabinoid receptor (CB1R), which is highly expressed in a variety of brain regions, including the hypothalamus [3-5]. The CB1R is a member of the $G$ protein-coupled receptor superfamily [6] which acts by inhibiting adenylate cyclase (AC) activity [7], delaying the opening of voltage-gated $\mathrm{N}$ - and $\mathrm{P} / \mathrm{Q}$-type channels [8-11], activating $\mathrm{K}^{+}$channels [12,13] and triggering MAP kinases signal cascades [14]. All these effects are originated from the activation of PTX-sensitive $G_{i, o}$ proteins coupled to $C B 1$ Rs, which inhibit AC activity and reduces cytoplasmic cAMP levels. Inhibition of AC and reduction of cAMP is a common pathway to most CB1R-mediated effects, but curiously enough, this pathway does not apply to the cannabinoid-induced modulation of voltage-gated $\mathrm{K}^{+}$and $\mathrm{Ca}^{2+}$ channels, which is medi-

\footnotetext{
* Corresponding author. Tel.: +39 011670 8489; fax: +39 0116708174.

E-mail address: emilio.carbone@unito.it (E. Carbone).

1 These two authors contributed equally to the work.
}

ated by $\mathrm{G}_{\mathrm{i}, \mathrm{o}}$ proteins acting directly on the channels, regardless of cAMP or any other diffusible messenger [15]. The only exception to this rule is the activation of the fast inactivating $I_{\mathrm{A}}$ potassium current induced by the CB1R/CB2R agonist WIN 55,212-2 in dissociated hippocampal neurons through a PTX- and cAMP/PKA-dependent pathway [16].

Cannabinoids act also on L-type $\mathrm{Ca}^{2+}$ channels (LTCCs) but, despite much work, the results remain controversial. CB1R activation could not affect $[9,17]$, up-regulate $[18,19]$ or inhibit LTCCs [20]. In arterial smooth muscles and in NTS (nucleus of tractus solitarius) neurons, activation of CB1R causes a voltage-independent inhibition of LTCCs which is prevented by PTX [21,22]. The inhibited current displays the same activation time course of controls (no delay of the rising phase) and the degree of inhibition remains unaltered after strong facilitatory prepulses, which are typical features of the LTCCs down-modulation in response to receptor-activated $\mathrm{G}_{\mathrm{i}, \mathrm{o}}$ proteins [23] (see [24] for a review). In addition, the inhibition of LTCCs by cannabinoids in NTS is mediated by cAMP and PKA. Blocking PKA or AC activity the inhibitory action of WIN 55,212-2 on LTCCs is prevented [22]. This is consistent with the effects of other $G$ protein-coupled receptor-mediated signaling on neuroendocrine LTCCs that are regulated by CAMP/PKA [25] and highlights the markedly different mechanism by which CB1R activation inhibits 
L- and non-L-type channels. Despite being PTX-sensitive, the latter action on non-L-type channels ( $\mathrm{N}$ and $\mathrm{P} / \mathrm{Q}$ ) is voltage-dependent and insensitive to cAMP [15].

Given the key role that LTCCs play in the control of many brain functions and the little knowledge on CB1R-mediated signal transduction mechanisms targeting these channels, we thought of interest to study the action of CB1R on LTCCs expressed in hypothalamic immortalized GT1-7 neurons. GT1-7 clonal cells produce and release the gonadotropin-releasing hormone (GnRH) [26]. They also express CB1Rs and are able to synthesize and release endocannabinoids [27]. GT1-7 neurons form stable networks that fire spontaneously and possess high densities of LTCCs. These channels play an important role in the control of synchronized firings and consequent pulsatile GnRH release [28,29]. In addition, cAMP signaling and a variety of $G$ protein-coupled receptors regulate $\mathrm{GnRH}$ release in GT1-7 neurons [30]. Thus, immortalized GnRH neurons appear to be an ideal model for studying the CB1R-mediated modulation of neuronal LTCCs.

We report here that the CB1R agonist WIN 55,212-2 selectively inhibits LTCCs in immortalized GT1-7 neurons. This selective action is mediated by PTX-sensitive $G_{i, o}$ proteins through a cAMP/PKA signal transduction pathway. Inhibition is voltage-independent and insensitive to short facilitatory prepulses excluding a direct $G_{i, 0^{-}}$ mediated action on the non-L-type channels expressed in GT1-7 cells (R-type; [31]). This new modulatory action on neuroendocrine LTCCs could be critical in the control of GnRH release in hypothalamic neurons and broadens the possible mechanisms by which cannabinoids could affect cell excitability, neuronal firing and $\mathrm{Ca}^{2+}$ dependent hormone release.

\section{Material and methods}

\subsection{Tissue culture of immortalized GT1-7 neurons}

Immortalized GT1-7 neurons (provided by Dr. P. Mellon, University of California, San Diego, La Jolla, USA) were cultured in $4.5 \mathrm{~g} / \mathrm{l}$ glucose Dulbecco's modified Eagle's medium (DMEM) supplemented with $10 \%$ fetal bovine serum, $2 \%$ of L-glutamine, $100 \mu \mathrm{U} / \mathrm{ml}$ penicillin and $100 \mu \mathrm{g} / \mathrm{ml}$ streptomycin in an atmosphere of $5 \% \mathrm{CO}_{2}$ at $37^{\circ} \mathrm{C}$. Morphological differentiation was optimized by culturing the cells just after they reached confluence in a medium containing B27 serum-free supplement, $1 \%$ sodium pyruvate, $0.5 \%$ fetal bovine serum and $2 \%$ of L-glutamine. The culture medium was changed every 3-4 days, and cells used in this study were between passages 9 and 14.

\subsection{Electrophysiology}

The $\mathrm{Ca}^{2+}$ currents were recorded by using two configurations: the perforated-patch with amphotericin B and the whole-cell. Patch electrodes were made of borosilicate glass capillaries and had a resistance of 1-2 M $\Omega$. For the perforated patch-clamp configuration [25], the pipette solution contained (in mM): $135 \mathrm{CsMeSO}_{3}$, $8 \mathrm{NaCl}, 2 \mathrm{MgCl}_{2}, 20$ HEPES and $50-100 \mu \mathrm{g} / \mathrm{ml}$ of amphotericin B (pH 7.3 with $\mathrm{CsOH}$ ); for the whole-cell configuration the solution contained (mM): $95 \mathrm{CsCl}, 30$ TEACl, 10 EGTA, $2 \mathrm{MgCl}_{2}, 10$ HEPES, 8 glucose, 2 ATP, 0.5 GTP, 15 phosphocreatine ( $\mathrm{pH} 7.3$ with $\mathrm{CsOH}$ ). The extracellular solution contained (in $\mathrm{mM}$ ): $135 \mathrm{TEACl}, 10 \mathrm{CaCl}_{2}$, $2 \mathrm{MgCl}_{2}, 10$ HEPES, 10 glucose ( $\mathrm{pH} 7.4$ with $\mathrm{CsOH}$ ).

Electrophysiological recordings were performed either using an EPC-9 patch-clamp amplifier and PULSE software (HEKA Electronic, Lambrecht, Germany) [25] or using an Axopatch 200-A amplifier and pClamp 10.0 software programs (Axon Instruments Inc., Foster City, CA, USA) [32]. Currents were sampled at $10 \mathrm{kHz}$ and filtered at $1-5 \mathrm{kHz}$. Recordings were made at room temperature.

\subsection{RNA extraction and PCR-RT for CB1R and CB2R in GT1-7 neurons}

Total RNA from GT1-7 cells was isolated with Mini RNeasy (Qiagen AG, Basel, Switzerland) as indicated in the manufacturer's instructions. DNase-treated total RNA was used in the reversed transcription (RT) procedure. cDNA was synthesized in a total volume of $50 \mu \mathrm{l}$ with the High Capacity cDNA Archive kit (Applied Biosystems, Foster City, CA, USA) according to the manufacturer's protocol. The primer sequences used were as follows: for CB1R (U22948), 5'-TGTGGGGAGAATTTTATGGA (forward) and 5'-AGATTGCAGCTTCTTGCAGT (reverse); for CB2R (NM 009924), 5'-GGTCCTCTCAGCATTGATTTCTTAC (forward) and 5'TTCACATCAGCCTCTGTTTCTGTA (reverse); for GAPDH (M32599) 5' CAACAGCAACTCCACTCTT (forward); 5'-AGGCCCCTCCTGTTATTATG (reverse). Polymerase chain reaction (PCR) was carried out in a total volume of $25 \mu \mathrm{l}$ containing $2 \mu \mathrm{l}$ of cDNA from the above reaction, $0.5 \mu \mathrm{M}$ of each specific primer, $0.5 \mathrm{U}$ Phusion DNA polymerase, $5 \times$ Phusion GC buffer, 0.2\% DMSO (FinnzymesOy, Espoo, Finland), $0.2 \mathrm{mM}$ of each deoxynucleotide triphosphate (Invitrogen, Carlsbad, CA, USA). The reaction conditions were $98^{\circ} \mathrm{C}$ for $30 \mathrm{~s}$, followed by 30 cycles (for CB1R and GAPDH) or 35 cycles (for CB2R) at $98^{\circ} \mathrm{C}$ for $15 \mathrm{~s}, 58^{\circ} \mathrm{C}$ for $30 \mathrm{~s}$, and $72^{\circ} \mathrm{C}$ for $30 \mathrm{~s}$. Positive controls (cDNA obtained from total mouse brain total RNA) and negative controls (water instead of template) were amplified in the same condition and glyceraldehyde-3-phosphate dehydrogenase was used to evaluate the integrity of RNA. The amplified products were separated on $2 \%$ agarose gels with Gel star (Cambrex Corporation, East Rutherford, NJ, USA) and in the presence of a $100 \mathrm{bp}$ DNA ladder as the molecular weight marker (Promega; Madison, WI, USA).

\subsection{Chemicals}

WIN 55,212-2, AM-251 and GDP- $\beta$-S were purchased from Tocris Bioscience (Avonmouth, UK). Nifedipine, 8-CPT-cAMP, and H89 were purchased from Sigma-Aldrich (Milano, Italy). All drugs were prepared just before use. WIN 55,212-2 and AM-251 were dissolved in dimethyl sulfoxide (DMSO) in stocks of $10 \mathrm{mM}$ and both used at the final concentration of $1-10 \mu \mathrm{M}$. GDP- $\beta-S$ was dissolved in water in stocks of $50 \mathrm{mM}$ and used at the final concentration of $170-500 \mu \mathrm{M}$. Nifedipine was dissolved in ethanol and prepared to the final concentration of $3 \mu \mathrm{M}$. PTX was purchased from Calbiochem Corporation (Darmstadt, Germany) and dissolved in water in stocks of $50 \mu \mathrm{g} / \mathrm{ml}$. GT1-7 neurons were incubated overnight with $130 \mathrm{ng} / \mathrm{ml}$ of toxin. 8-CPT-CAMP and $\mathrm{H} 89$ were dissolved in water in stocks of $10 \mathrm{mM}$ and $1 \mathrm{mM}$ and used at the final concentration of $1 \mathrm{mM}$ and $5 \mu \mathrm{M}$, respectively.

\subsection{Statistical analysis}

The results are expressed as the mean \pm S.E.M. for $n$ number of neurons. The differences were analyzed by either one-sample or paired Student's $t$-tests as indicated. Values of $p<0.05$ were considered statistically significant.

\section{Results}

\subsection{Expression of CB1R and CB2R in GT1-7 neurons}

The presence of cannabinoid receptors (CB1R and CB2R) in GT1-7 neurons was supported by qualitative RT-PCR experiments performed on the total RNA extracted from GT1-7 cells and mouse brain RNA (positive control). Total RNA extracted was retro-transcribed and amplified with specific oligonucleotides for CB1R and CB2R. To evaluate RNA integrity we used primers for GAPDH (glyceraldehyde-3-phoshate dehydrogenase) specifically 
(A)

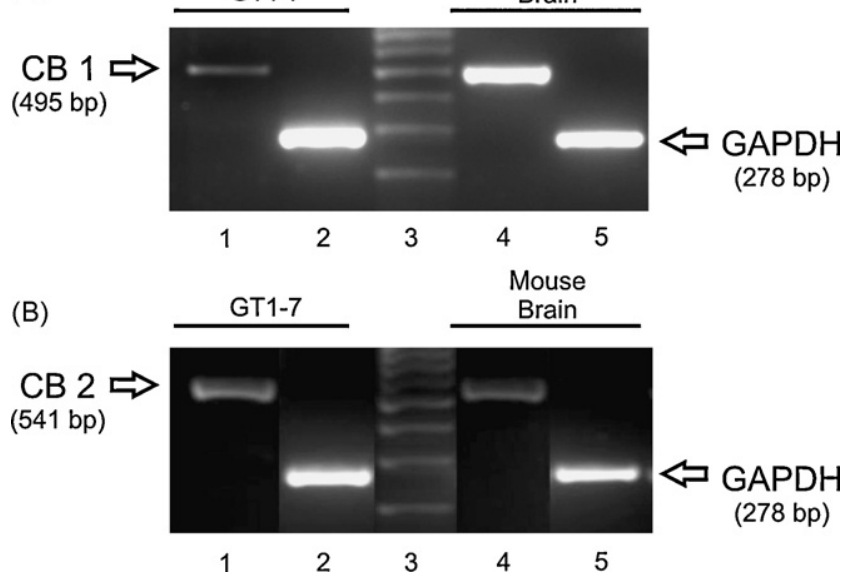

Fig. 1. RT-PCR demonstrates the presence of $C B 1 R$ and $C B 2 R$ mRNA in GT1-7 neurons. (A) RT-PCR analyses of CB1R expression in GT1-7 cells (lane 1). Lanes 1 and 2 show samples from GT1-7 cells, lanes 4 and 5 are from mouse brain (positive control). The enzyme GAPDH (lanes 2 and 5 ) was used as housekeeping gene. Products were separated via electrophoresis on $2 \%$ agarose gel containing ethidium bromide in the presence of specific molecular weights (MW) (lane 3). (B) RT-PCR analyses of CB2R expression in GT1-7 cells (lane 1 ). Lanes 1 and 2 show template from GT17; lanes 4 and 5 show samples from mouse brain (positive control). Lane 3 is the molecular weights marker.

expressed in GT1-7 cells and mouse brain. Qualitative RT-PCR shows the presence of both cannabinoid receptors in GT1-7 neurons: CB1R mRNA (lane 1, Fig. 1A) and CB2R mRNA (lane 1, Fig. 1B). As positive control, expression of CB1R and CB2R was evaluated in the mouse brain (lane 4, Fig. 1A and B) and GAPDH was used as housekeeping gene (lanes 2 and 5; Fig. $1 \mathrm{~A}$ and $\mathrm{B}$ ).

\subsection{LVA and HVA $\mathrm{Ca}^{2+}$ currents in GT1-7 neurons}

GT1-7 neurons express low-voltage activated (LVA, T-type) and high-voltage activated (HVA) $\mathrm{Ca}^{2+}$ channels [33]. The HVA component is further subdivided in two channel types ( $L$ and $R$ ) with percentages of expression varying from cell to cell $[31,28]$. We found on average that $30 \%$ of GT1-7 neurons expressed fast inactivating T-type channels that activated from $-50 \mathrm{mV}$ in $10 \mathrm{mM}$ $\mathrm{Ca}^{2+}$ (holding potential, $V_{\mathrm{h}},-80 \mathrm{mV}$ ) and reached maximal amplitudes at $-10 \mathrm{mV}$ (Fig. 2A and B). Slowly inactivating HVA channels were found to activate above $-40 \mathrm{mV}$ (Fig. 2C) and reached maximal amplitudes at $+10 \mathrm{mV}$ (Fig. 2D). $\mathrm{HVA} \mathrm{Ca}^{2+}$ currents had mean amplitudes of $196.6 \pm 16.6 \mathrm{pA}$ at $+10 \mathrm{mV}(n=81)$ that normalized for the cell capacitance $(33.2 \pm 3.2 \mathrm{pF} ; n=81)$ gave mean current densities of $5.9 \pm 0.8 \mathrm{pA} / \mathrm{pF}$. The T-type channels had the typical gating characteristics described in these [28] and other neurons [34]. They activated below $-40 \mathrm{mV}$, had voltage-dependent activation and fast inactivation and were inactivated at $V_{\mathrm{h}}$ around $-50 \mathrm{mV}$. Their presence caused rapid inactivating currents during step depolarization and an early current peak around $-10 \mathrm{mV}$ during ramp commands (Fig. 2B). In this work the T-type channels were not further considered.

To simplify our analysis, we tested the percentage of LTCCs expressed by GT1-7 neurons by determining the blocking effects of $3 \mu \mathrm{M}$ nifedipine. We found that the DHP-antagonist on average blocked $49.4 \pm 3.0 \%(n=12)$ of the total HVA currents activated at $+10 \mathrm{mV}$ from $V_{\mathrm{h}}=-80 \mathrm{mV}$ (Fig. $3 \mathrm{~A}$ and C). DHP block was fast and reversible and, could be complete in $30 \%$ of the cells, indicating the presence of only LTCCs in a fraction of GT1-7 neurons (Fig. 3B). The residual DHP-resistant currents ( $~ 50 \%$ of the total) were not further pharmacologically dissected and, from here on, will be indicated as the non-L-type current component (Fig. 3C). In previous studies the HVA $\mathrm{Ca}^{2+}$ currents of GT1-7 neurons were identified mainly as LTCCs (100\% of the total) [28] or carried mostly by R-type chan-
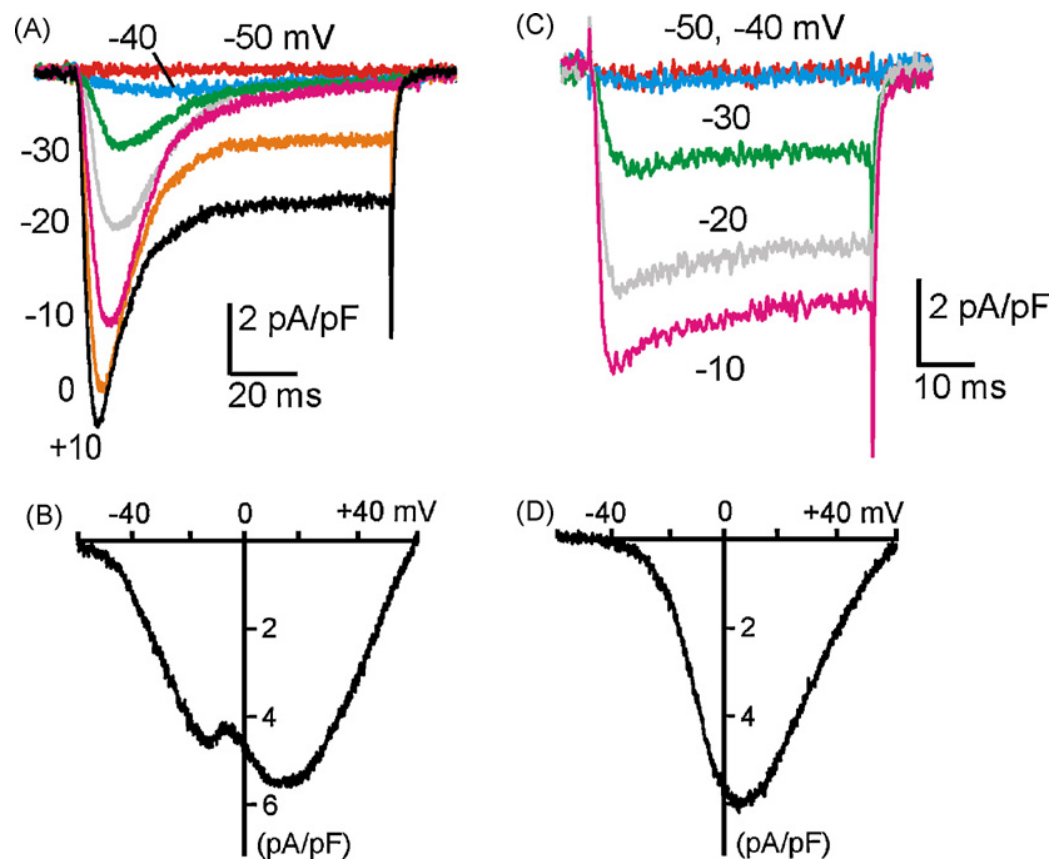

Fig. 2. $\mathrm{Ca}^{2+}$ currents in GT1-7 neurons expressing different percentages of LVA (T-type) and HVA (L- and non-L-type) channels. (A) Overlapped Ca ${ }^{2+}$ current traces recorded in $10 \mathrm{mM} \mathrm{Ca}^{2+}$ from a GT1-7 neuron expressing high densities of T-type channels. Step depolarizations were from -50 to $+10 \mathrm{mV}$. The holding potential $\left(V_{\mathrm{h}}\right)$ was $-80 \mathrm{mV}$. (B) $I-V$ characteristics recorded from a GT1-7 neuron expressing T-type and HVA Ca ${ }^{2+}$ channels using a ramp command from -60 to $+60 \mathrm{mV}\left(V_{\mathrm{h}}-80 \mathrm{mV}\right)$. Notice the typical doublepeak indicative of the presence of LVA and HVA channels. (C and D) Overlapped $\mathrm{Ca}^{2+}$ current traces and $I-V$ characteristics recorded from two GT1-7 neurons expressing mostly HVA channels. Sequential step depolarizations in $(C)$ were from -50 to $-10 \mathrm{mV}\left(V_{\mathrm{h}}-80 \mathrm{mV}\right)$; traces at more positive potentials are not shown to avoid confusing overlapping. The ramp command was as in (B). Notice the absence of the "early shoulder" associated to T-type currents. 


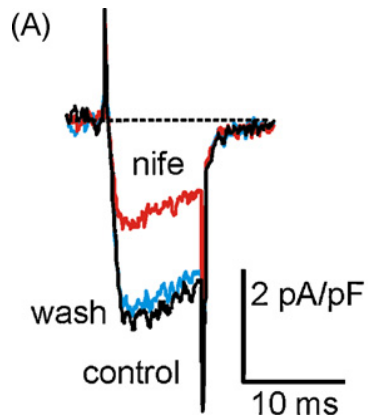

(B)

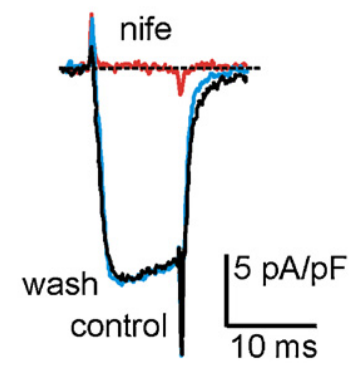

(C)

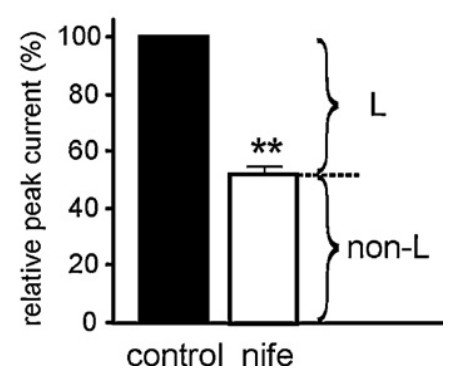

Fig. 3. GT1-7 neurons express different densities of LTCCs. (A and B) Two examples of $\mathrm{Ca}^{2+}$ current block recorded at $+10 \mathrm{mV}\left(V_{\mathrm{h}}-80 \mathrm{mV}\right.$ ) from neurons with different sensitivity to nifedipine $(3 \mu \mathrm{M})$. In (A) the DHP blocked nearly $50 \%$ of the control current (red trace) while in (B) the DHP blocked completely the total current. In both cases the DHP action was fully reversible (blue trace). (C) Mean percentage of current amplitude in the presence of $3 \mu \mathrm{M}$ nifedipine from GT1-7 neurons responding partially to the DHP $(n=12)$. The percentage of current is expressed relative to the peak control current $\left({ }^{* *} p<0.01\right.$ vs. control using a one-sample analysis Student's $t$-test when comparing the mean percentage values to hundred).

nels ( $75 \%$ of the total) [31]. Our data are in fair agreement with both reports indicating significant degree of heterogeneity of $\mathrm{Ca}^{2+}$ channels expression in GT1-7 neurons, which might derive from different tissue culture conditions.

\section{3. $\mathrm{Ca}^{2+}$ currents inhibition by WIN $55,212-2$ is voltage-independent}

GT1-7 cells express CB1R (Fig. 1) and recent works have shown that their activation by WIN 55,212-2 reduces the release of GnRH from these cells [27]. A likely mechanism is that WIN 55,212-2 might block the LTCCs that control both, the rate of synchronized action potential firing and pulsatile GnRH release [29]. We tested therefore the effects of WIN 55,212-2 on the $\mathrm{Ca}^{2+}$ currents activated at $+10 \mathrm{mV}$ using saturating concentrations $(1-10 \mu \mathrm{M})$ and looked for its effects on the amplitude and kinetics of $\mathrm{Ca}^{2+}$ currents. Direct application of WIN 55,212-2 on GT1-7 neurons produced an average $\mathrm{Ca}^{2+}$ current inhibition of $34.4 \pm 1.6 \%(n=13 ; p<0.01$ respect to normalized control) (Fig. 4A-C). The inhibition was fast, reversible and required less than 1 min to reach maximal values (Fig. 4D). Recovery had similar kinetics to the onset of inhibition.

$\mathrm{Ca}^{2+}$ current inhibition by WIN 55,212-2 was of the same percentage at every potential and had no marked effects on the time course and voltage-dependence of channel activation. The half-time to peak at $+10 \mathrm{mV}$ was $0.76 \pm 0.17 \mathrm{~ms}$ in control and $0.75 \pm 0.15 \mathrm{~ms}$ with WIN $55,212-2(n=8)$. In addition, the $I-V$ curve from -60 to $+60 \mathrm{mV}$ in the presence of the CB1R agonist had the same shape of the control $I-V$ and was simply scaled-down by a constant factor (Fig. 4B). This is a clear indication that WIN 55,212-2 action is voltage-independent and thus different from the voltage-

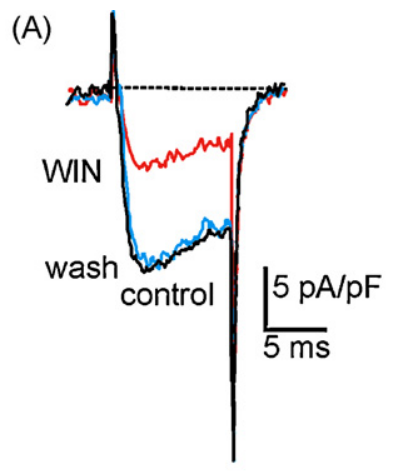

(D)

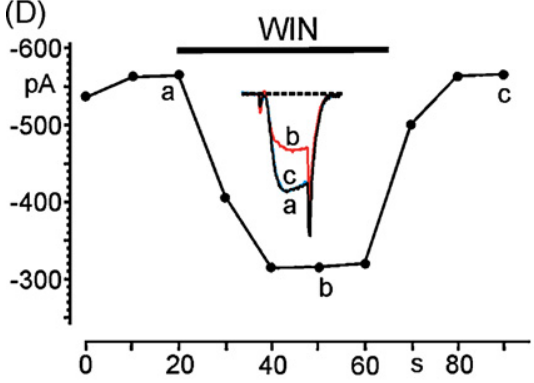

(B)

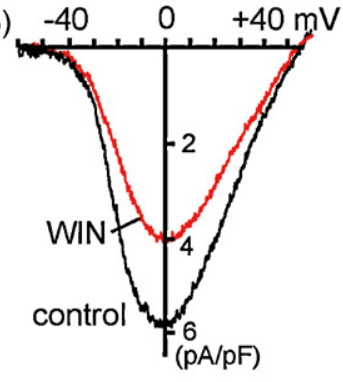

(C)

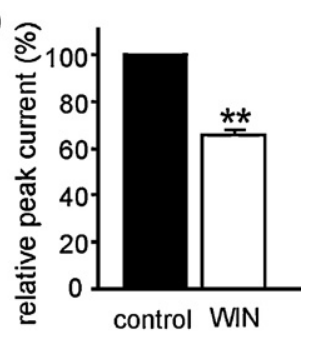

(E)

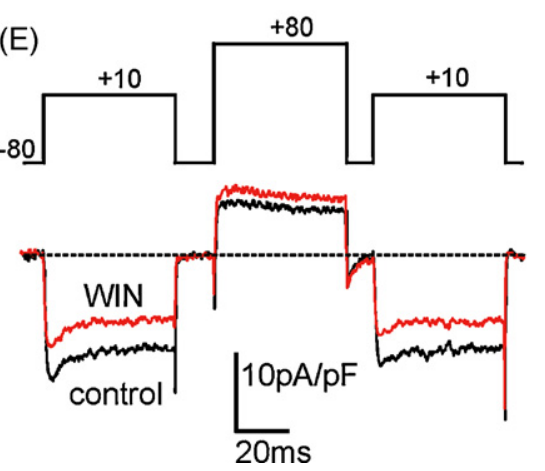

Fig. 4. Inhibition the $\mathrm{Ca}^{2+}$ currents by WIN 55,212-2 in GT1-7 neurons is voltage-independent. (A) Current traces recorded at $+10 \mathrm{mV}$ from a GT1-7 neuron before (control, black trace), during (WIN, red trace) and after (wash, blue trace) exposure of $10 \mu \mathrm{M}$ WIN 55,212-2. (B) $I-V$ characteristics in control conditions and during application of $10 \mu \mathrm{M}$ WIN 55,212-2. Notice the proportional decrease of the current with WIN 55,212-2 at every potential. (C) Mean percentage of current amplitude in the presence of $10 \mu \mathrm{M}$ WIN 55,212-2 obtained from $n=13$ neurons. The percentage of current is expressed relative to the peak control current $\left({ }^{* *} p<0.01\right.$ vs. control using a one-sample analysis Student's $t$-test when comparing the mean percentage values to hundred). (D) Time course of peak $\mathrm{Ca}^{2+}$ currents at $+10 \mathrm{mV}$ before, during and after addition of $10 \mu \mathrm{M}$ WIN 55,212-2. In the inset are shown the current traces recorded at the time indicated by the letters (a-c). (E) Ca ${ }^{2+}$ currents at control (black trace) and during exposure of $10 \mu \mathrm{M}$ WIN 55,212-2 (red trace) recorded using the double-pulse protocol illustrated on the top. The prepulse depolarization to $+80 \mathrm{mV}$ was not able to relieve the inhibition of the $\mathrm{Ca}^{2+}$ current induced by WIN 55,212-2. 

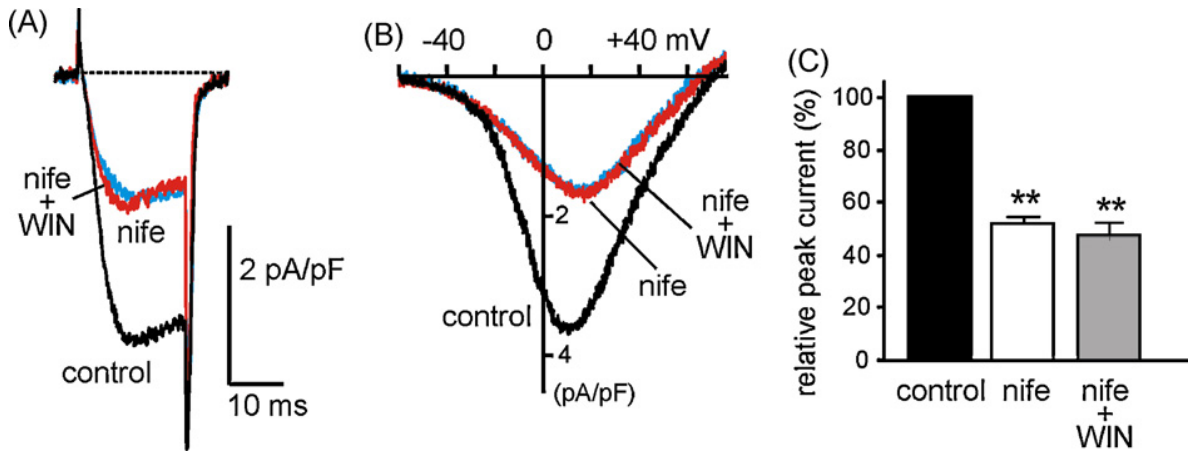

Fig. 5. The $\mathrm{Ca}^{2+}$ current inhibition induced by WIN 55,212-2 is selective for LTCCs. (A and B) Current traces recorded at $+10 \mathrm{mV}$ and $I-V$ characteristics at control (black trace), in the presence of $3 \mu \mathrm{M}$ nifedipine (red trace) and during application of nifedipine plus $10 \mu \mathrm{M}$ WIN 55,212-2 (blue trace) from a GT1-7 neuron. (C) Mean peak current amplitudes recorded at $+10 \mathrm{mV}$ in the presence of nifedipine and nifedipine plus WIN 55,212-2 $(n=11)$. The relative peak current values are normalized with respect to control $\left({ }^{* *} p<0.01\right.$ vs. control using a one-sample analysis Student's $t$-test when comparing the mean percentage values to hundred).

dependent inhibition induced by cannabinoids in cell preparations expressing $\mathrm{N}$ and $\mathrm{P} / \mathrm{Q}$-type channels [9]. $\mathrm{Ca}^{2+}$ current inhibition by WIN 55,212 in these cases produced a net delay of $\mathrm{Ca}^{2+}$ channel activation at voltages below $+10 \mathrm{mV}$ that was largely relieved at more positive potentials (>+40 mV). Strong prepulses of $50 \mathrm{~ms}$ to $+80 \mathrm{mV}$ anticipating the test pulse could relief most of the inhibition [10]. In the case of GT1-7 neurons the same strong prepulses to $+80 \mathrm{mV}$ $(n=11)$ was unable to remove the inhibition induced by WIN 55,212-2. Percentage of $\mathrm{Ca}^{2+}$ current depression with WIN 55,212-2 (34\%) was identical before and after the prepulse (Fig. 4E), indicating that WIN 55,212-2 action was voltage-independent. There was neither an acceleration of $\mathrm{Ca}^{2+}$ current activation nor an increase of peak amplitude after the prepulse which could suggest a facilitatory effect of voltage as for $\mathrm{N}$ - and P/Q-type channels (see [35] for a review).

\subsection{WIN 55,212-2 and the CB1R inverse agonist AM-251 act selectively on LTCCS}

The inhibitory effects of WIN 55,212-2 are selective for LTCCS and prevented by nifedipine. In the presence of the DHP $(3 \mu \mathrm{M})$, WIN 55,212-2 had no further inhibitory effects during step depolarization to $+10 \mathrm{mV}$ (Fig. $5 \mathrm{~A}$ ) or during ramp commands (Fig. 5B). This was systematically observed in eleven GT1-7 neurons in which the relative peak amplitude of the current with nifedipine was $52.7 \pm 4.9 \%$ with respect to control and decreased to $47.4 \pm 4.8 \%$ after addition of WIN 55,212-2 (Fig. 5C).

Further support to a specific effect of CB1Rs activation on LTCCs in GT1-7 neurons comes from the observation that the selective CB1R inverse agonist AM-251 produced an effect opposite to WIN $55,212-2$. AM-251 $(10 \mu \mathrm{M})$ caused a net up-regulation of $\mathrm{Ca}^{2+}$ cur-
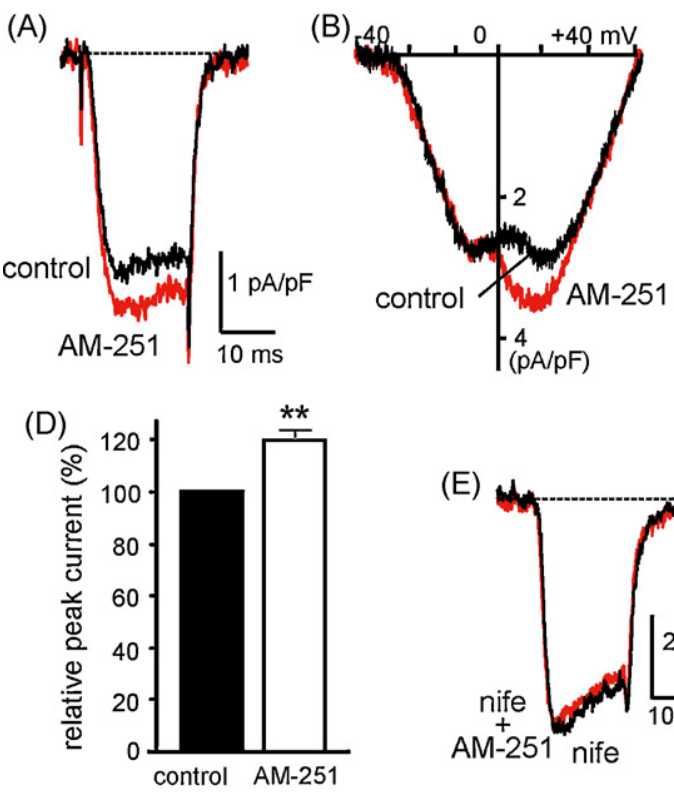

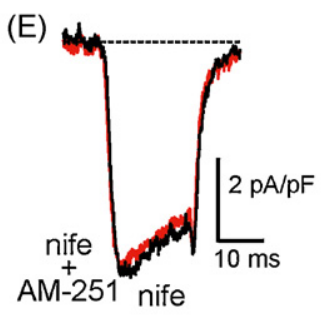

Fig. 6. The CB1R inverse agonist AM-251 up-regulates LTCCs in GT1-7 neurons. (A and B) Current traces recorded at $+10 \mathrm{mV}$ and $I-V$ characteristics at control (black trace) and during application of $10 \mu \mathrm{M}$ AM-251 (red trace) in two different GT1-7 neurons. Notice in (B) the selective increase of the second peak associated to the HVA currents. (C) Time course of peak $\mathrm{Ca}^{2+}$ currents at $+10 \mathrm{mV}$ before, during and after addition of $10 \mu \mathrm{M} \mathrm{AM}-251$. In the inset are shown the current traces recorded at the time indicated by the letters $(\mathrm{a}-\mathrm{c})$. (D) Mean percentage of current amplitude in the presence of $10 \mu \mathrm{M}$ AM-251 from $n=8$ GT1-7 neurons. The percentage is expressed relative to the peak control current $\left({ }^{* *} p<0.01\right.$ vs. control using a one-sample analysis Student's $t$-test when comparing the mean percentage values to hundred). (E) Current traces recorded at $+10 \mathrm{mV}$ in the presence of $3 \mu \mathrm{M}$ nifedipine (black trace) and during application of nifedipine plus $10 \mu \mathrm{M}$ AM-251 (red trace) from a GT1-7 neuron. (F) Mean peak current amplitudes recorded at $+10 \mathrm{mV}$ in the presence of nifedipine and nifedipine plus AM-251 $(n=8)$. The relative peak current values are normalized with respect to control $(* * p<0.01$ vs. control calculated as in (D). 
rents at $+10 \mathrm{mV}$ (Fig. $6 \mathrm{~A}$ ). The up-regulation was selective for the HVA Ca ${ }^{2+}$ channels (Fig. 5B), required 1-2 min to reach maximal values (Fig. 5C), and was systematically observed in every GT17 neuron tested $(n=8)$. The percentage of up-regulation relative to control varied from 6 to $44 \%$ with a mean value of $19.7 \pm 4.9 \%$ ( $p<0.01$ vs. normalized control; Fig. 6D) and was fully prevented by $3 \mu \mathrm{M}$ nifedipine (Fig. $6 \mathrm{E}$ ). Simultaneous application of AM-251 and nifedipine caused no further decrease of the peak current than the DHP alone (Fig. 6E). Mean relative amplitudes of $\mathrm{Ca}^{2+}$ currents were $53.5 \pm 4.2 \%$ with nifedipine and $50.2 \pm 6.7 \%$ with nifedipine plus AM-521.

\subsection{WIN 55,212-2 action is prevented by PTX cell incubation and intracellular GDP- $\beta-S$}

A CB1Rs hallmark is that their action on $\mathrm{Ca}^{2+}$ and $\mathrm{K}^{+}$channels is mediated by PTX-sensitive $G_{i, o}$ proteins [15]. Overnight cell incubation with PTX is sufficient to uncouple the CB1R from $G_{i, o}$ proteins and prevents most of the effects mediated by cannabinoids [7]. The same occurred for the CB1R-mediated effects on $\mathrm{Ca}^{2+}$ channels in GT1-7 neurons (Fig. 7A-C). When testing the effects of WIN 55,2122 on a group of eight PTX-treated neurons, four of them responded with a partial up-regulation of $\mathrm{Ca}^{2+}$ currents (mean 11.5\%) and no changes to the $I-V$ characteristics (Fig. 7A and C), two had no response and two responded with a partial inhibitory effect (mean $16.5 \%$ ) (Fig. 7B). Taken together, these findings suggest that after PTX treatment the inhibitory action of WIN 55,212-2 on LTCCs is abolished or strongly reduced and prove the existence of a receptormediated effect of cannabinoids in GT1-7 cells.

To further confirm the involvement of a $G_{i, o}$ protein in the cannabinoid-mediated inhibition of LTCCs we tested whether also the non-hydrolysable GDP analog, GDP- $\beta-S$, could prevent the inhibitory effects of WIN 55,212-2. Fig. 7D shows an example of a GT1-7 neuron internally perfused with $170 \mu \mathrm{M}$ GDP- $\beta-S$. The neuron initially responded to WIN 55,212-2 with a partial inhibition, but after few minutes the inhibition was removed. In eight cells tested, $170-500 \mu \mathrm{M}$ GDP- $\beta$-S could remove completely the effects of WIN 55,212-2 (Fig. 7E). We also noticed that in most GT1-7 neurons GDP- $\beta$-S produced a sizeable up-regulation of control currents (10-20\%), supporting the idea that a fraction of LTCCs are likely inhibited at rest due to a basal activity of CB1R attributed to a constitutive (agonist-independent) receptor activity.

\subsection{WIN 55,212-2 effects are mediated via a cAMP/PKA pathway}

Given that $G_{i, o}$ proteins mediate the effect of WIN 55,2122 , the next issue was to assay whether the $G$ protein-mediated inhibition was direct on LTCCs [23] or indirect through a reduction of adenylate cyclase activity with a consequent lowering of CAMP and PKA-mediated LTCC phosphorylation [22]. For this reason, we first tested whether the PKA inhibitor H89 could prevent the WIN 55,212-2 effects. We found that either acute application (Fig. 8A) or cell pre-incubation with $5 \mu \mathrm{M}$ H89 (Fig. 8B) were both able to prevent LTCC inhibition. In the case of Fig. 8A, WIN

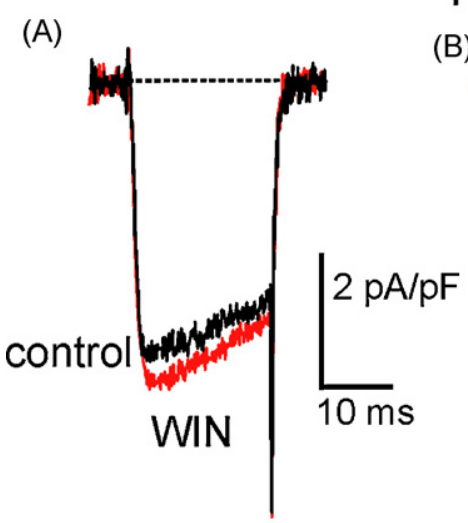

PTX-treated cells
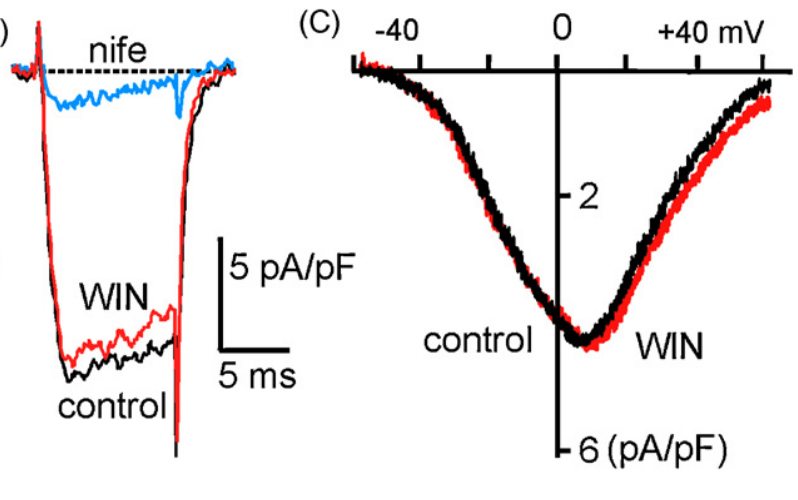

\section{GDP- $\beta-S$}

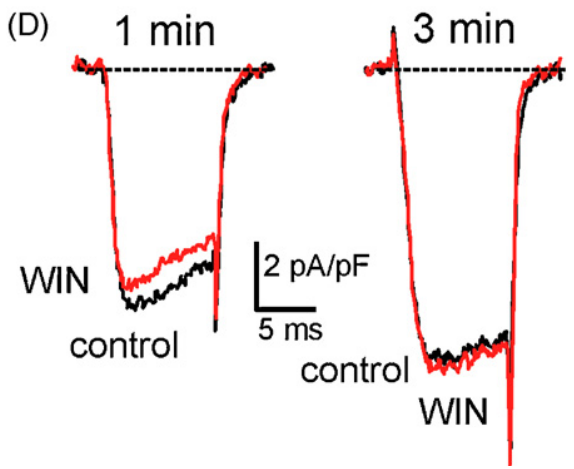

(E)

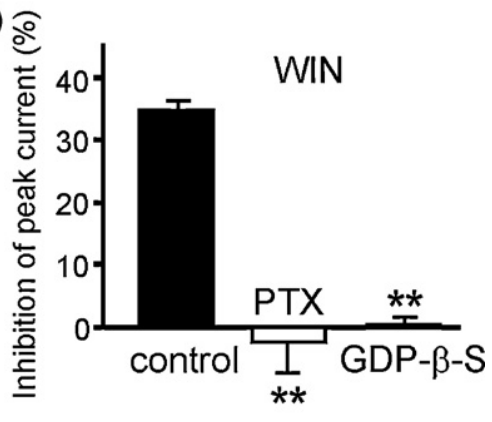

Fig. 7. PTX and GDP- $\beta$-S prevent the inhibitory WIN 55,212-2 action on $\mathrm{Ca}^{2+}$ current in GT1-7 neurons. (A and B) Effects of $10 \mu \mathrm{M}$ WIN $55,212-2$ on Ca ${ }^{2+}$ currents recorded at $+10 \mathrm{mV}$ in two GT1-7 neurons incubated overnight with $130 \mathrm{ng} / \mathrm{ml}$ PTX. In (A) the CB1R agonist caused a slight Ca ${ }^{2+}$ current increase, while in (B) caused a slight decrease. Nifedipine $(3 \mu \mathrm{M})$ was added after testing WIN 55,212-2. (C) I-V characteristics in control conditions (black trace) and during application of $10 \mu \mathrm{M}$ WIN $55,212-2$ (red trace) in a GT1-7 neuron pre-incubated with PTX. (D) Effects of $10 \mu \mathrm{M}$ WIN 55,212-2 on Ca ${ }^{2+}$ currents recorded at $+10 \mathrm{mV}$ in a GT1-7 neuron intracellularly perfused with $170 \mu \mathrm{M}$ GDP- $\beta$-S soon after having established low-resistance whole-cell recording conditions ( $t=1 \mathrm{~min}$ ) and 2 min later $(t=3 \mathrm{~min})$. Notice the disappearance of the WIN $55,212-2$-induced inhibition and the increased current amplitude after time. (E) Percentage inhibition induced by WIN 55,212-2 in control cells (data are derived from Fig. 4C; $n=13)$, after PTX treatment $(n=8)$ or during prolonged GDP- $\beta-S$ intracellular application $(n=8)\left({ }^{* *} p<0.01\right.$ vs. control using Student's paired $t$-tests). 
(A)

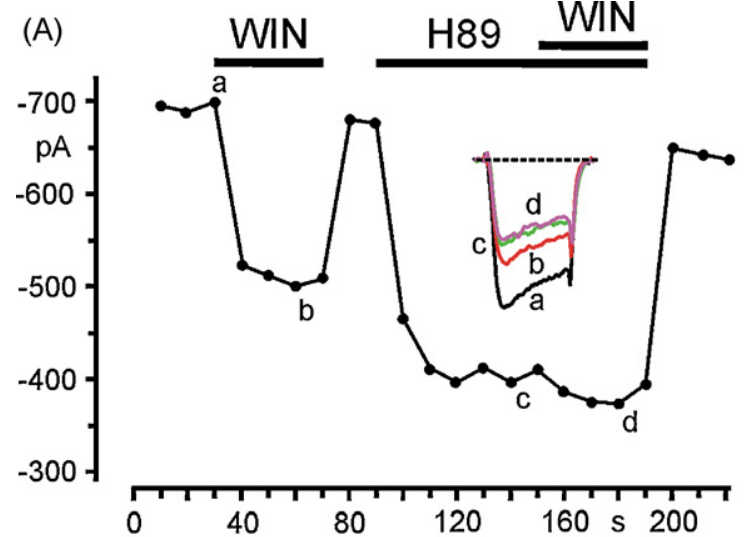

(C)
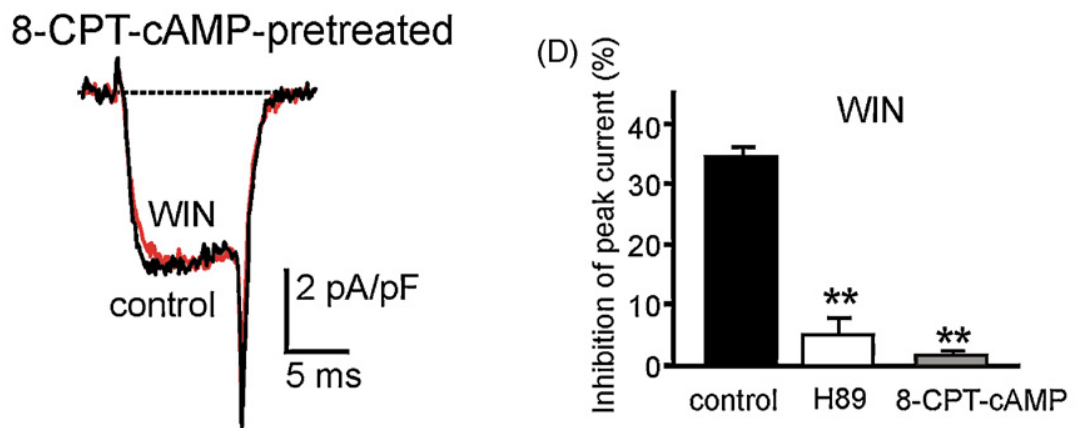

(B) H89-pretreated

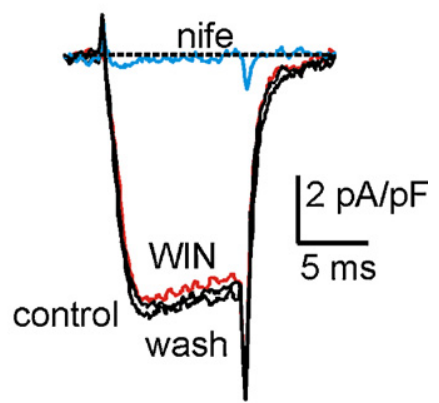

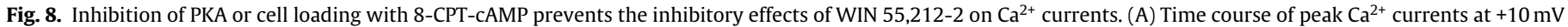
during WIN 55,212-2 (10 $\mu \mathrm{M}), \mathrm{H} 89(5 \mu \mathrm{M})$ and H89 + WIN 55,212-2 exposure, as indicated by the horizontal bars. In the inset are shown the current traces recorded at the time indicated by the letters (a-d). (B) Effects of WIN 55,212-2 on $\mathrm{Ca}^{2+}$ currents recorded at $+10 \mathrm{mV}$ in a GT1-7 neuron incubated for 30 min with $5 \mu \mathrm{M}$ H89. After testing WIN 55,212-2 effects, the $\mathrm{Ca}^{2+}$ current was assayed for its sensitivity to $3 \mu \mathrm{M}$ nifedipine (blue trace), unmasking a nearly complete contribution of LTCCs. (C) Effects of WIN $55,212-2$ on $\mathrm{Ca}^{2+}$ currents recorded at $+10 \mathrm{mV}$ in a GT1-7 neuron incubated for 30 min with $1 \mathrm{mM} 8$-CPT-cAMP. (D) Percentage inhibition induced by WIN 55,212-2 in control cells (data are derived from Fig. 4C; $n=13)$, after chronic or acute application of H89 $(n=8)$ or cell loading with 8 -CPT-cAMP $(n=4)(* * p<0.01$ vs. control using Student's paired $t$-tests).

$55,212-2$ alone caused about a $35 \%$ inhibition of the total $\mathrm{Ca}^{2+}$ current while after applying $\mathrm{H} 89$ the inhibitory effect was strongly prevented $(n=5)$. WIN 55,212-2 had also no effects when GT1-7 neurons were incubated for $30 \mathrm{~min}$ in a solution containing $5 \mu \mathrm{M}$ H89 $(n=3)$. In Fig. 8 B, the neuron was pre-incubated with H89 and WIN 55,212-2 had no effect on the $\mathrm{Ca}^{2+}$ current at $+10 \mathrm{mV}$ that was fully blocked by nifedipine. On a total of eight cells pretreated with H89 (acutely or chronically), WIN 55,212-2 caused a mean inhibition of $5.1 \pm 4.5 \%$ which was significantly smaller than the mean inhibition induced by WIN 55,212-2 alone (black bar in Fig. 8E).

To further prove that CB1R activation proceeds via the inhibition of the CAMP/PKA pathway we also tested whether loading GT1-7 neurons with 8-CPT-cAMP could prevent the cannabinoidinduced inhibition on LTCCs. In four cells pre-incubated for $30 \mathrm{~min}$ in a solution containing $1 \mathrm{mM}$ 8-CPT-CAMP, WIN 55,212-2 had practically no inhibitory effects (Fig. $8 C$ and $D$ ). This suggests that maintaining high levels of intracellular cAMP can preserve LTCCs functioning, regardless of any active $G_{i, o}$ protein-mediated inhibition of adenylate cyclase. The results of Fig. 8 do also exclude that CB1R-activated $G_{i, o}$ proteins act directly on LTCCs, as it occurs for the CB1R-mediated inhibition of $\mathrm{N}$ - and P/Q-type $\mathrm{Ca}^{2+}$ channels in cells expressing CB1R $[9,10]$.

\section{Discussion}

We provided evidence that LTCCs of hypothalamic immortalized GT1-7 neurons are selectively inhibited by the CB1 cannabinoid receptor through $\mathrm{G}_{\mathrm{i}, \mathrm{o}}$ proteins and cAMP/PKA-mediated pathway. The mechanism of LTCCs inhibition fulfills the main features of
CB1R action which involves the activation of PTX-sensitive $G_{i, o}$ proteins and the reduction of CAMP/PKA activity [7]. There is a number of evidence supporting this conclusion. The inhibitory effect of the cannabimimetic agonist WIN 55,212-2 is fully prevented by nifedipine and the CB1R inverse agonist AM-251 produces an up-regulation of LTCCs. The action of WIN 55,212-2 is abolished by PTX cell incubation, intracellular GDP- $\beta-S$ application, specific PKA inhibition and by treatment with hydrolysis-resistant cAMP analogues.

\subsection{L-type versus non-L-type channel modulation by cannabinoids}

Our data clearly show that WIN 55,212-2 selectively affects LTCCs without affecting non-L-type channels. Since GT1-7 cells mainly express T-, L- and R-type channels [28,31], this implies that the T- and R-type are unlikely the target of CB1R activation in these neurons. These results are in good agreement with previous works reporting no effects on native T-type channels in the neuroblastoma-glioma NG108-15 cell line using low concentrations of WIN 55,212-2 [9] but diverge from the effects on heterologously expressed $\mathrm{Ca}_{\mathrm{v}} 3$ channels which are depressed by CB1 $R$ activation [36,37]. In this case, however, the cannabimimetic agonists act directly on the $\mathrm{Ca}_{\mathrm{v}} 3$ channel isoforms and independently of CB1R activation. Also the lack of effects on R-type channels is in agreement with previous works reporting no action on somatic R-type channels in central neurons $[22,38]$ but it is at variance with the observation that presynaptic R-type channels are effectively inhibited by cannabimimetic agonists at the granule cell-Purkinje neuron synapses [39]. These contrasting results 
reflect most likely the heterogeneous nature of neuronal R-type channels [40].

At variance with the divergent findings on T- and R-type channels, there is converging evidence that CB1R activation inhibits $\mathrm{N}$ and $\mathrm{P} / \mathrm{Q}$-type channels in a voltage-dependent manner [9-11,15]. The inhibition is rapid and mediated by PTX-sensitive $\mathrm{G}_{\mathrm{i}, \mathrm{o}}$ proteins. It closely resembles the one mediated by the $G_{i} \beta \gamma$ subunit and associated to most $G$ protein-coupled receptors [41] (see [35] for a review). The main effect of this "membrane-delimited" modulation is a delayed $\mathrm{Ca}^{2+}$ channel activation at low voltages, which accelerates at higher potentials $[42,43]$. The slow activation derives from a prolonged latency of first channel opening [44] and is fully recovered by applying strong positive prepulses [45]. After prepulse, the $\mathrm{N}$ - and $\mathrm{P} / \mathrm{Q}$-type currents are facilitated: they recover their normal activation time course and increase their amplitude. This phenomenon is commonly indicated as "voltage-dependent" $\mathrm{Ca}^{2+}$ channel facilitation. There is, however, evidence of a direct inhibition of P-type channels by endocannabinoids in cerebellar Purkinje neurons that is voltage-independent and not mediated by CB1R [46].

The CB1R-mediated inhibition of LTCCs reported here is markedly different from that described for $\mathrm{N}$ - and $\mathrm{P} / \mathrm{Q}$-type channels and in good agreement with previously reported CB1Rmediated effects on LTCCs. WIN 55,212-2 produces a $35 \%$ inhibition of the total HVA current without altering the activation time course and strong positive prepulses do not induce any facilitation (acceleration of channel activation and amplitude increase). This $\mathrm{Ca}^{2+}$ channel modulation is usually indicated as "voltage-independent" [23] (see [47] for a review). Common to the N- and P/Q-type channels, the cannabinoids-mediated inhibition of LTCCs in GT17 neurons is mediated by PTX-sensitive $G_{i, o}$ proteins but differs markedly for its sensitivity to the cAMP-dependent PKA pathway. $\mathrm{N}$ - and $\mathrm{P} / \mathrm{Q}$-type channels inhibition occurs independently of diffusible messengers, while LTCCs inhibition is modulated by cAMP and PKA. Blocking PKA or preserving high levels of 8-CPT-cAMP analogues do prevent the inhibitory effects of WIN 55,212-2 on LTCCs.

The modulation of LTTCs in GT1-7 cells is very similar to the voltage-independent inhibition of LTCCs induced by WIN 55,212-2 in NTS (nucleus tractus solitarius) neurons [22]. In these neurons, activation of CB1R selectively inhibits the LTCCs in a voltage-independent manner, with no effects on non-L-type channels ( $\mathrm{N}-, \mathrm{P} / \mathrm{Q}-$ and $\mathrm{R}$ ), while $\mu$ - and $\kappa$-opioid agonists selectively inhibit the $\mathrm{N}$ - and $\mathrm{P} / \mathrm{Q}$-type currents in a voltage-dependent manner. As for GT1-7 cells, the inhibition of LTCCs in NTS neurons is reversible, cAMP/PKA-dependent and occurs within short times (20-30 s), suggesting rather close coupling between CB1Rs, $\mathrm{G}_{\mathrm{i}, \mathrm{o}}$ proteins, adenylate cyclases, cAMP/PKA and LTCCs. This is somehow at variance with the slow up-regulatory effects of $G$ protein-coupled receptors mediated by the cAMP/PKA pathway on LTCCs in myocytes [48], neuroendocrine cells [24,25,49,50], and neuronal dendrites [51] (see [52] for a review). The most likely explanation is that LTCCs modulation by cAMP/PKA is critically controlled by the co-localization of $G$ protein-coupled receptors, $\mathrm{Ca}_{\mathrm{v}} 1.2$ channels, adenylate cyclase and A-kinase anchoring proteins (AKAPs) (reviewed by [53]) and thus its onset and offset could vary greatly in different cell preparations. A possible difference could derive from the type of LTCC involved. GT1-7 cells express only $\mathrm{Ca}_{\mathrm{v}} 1.3$ channels [31] whose modulation is not yet well studied.

Inhibition of LTCCs by WIN 55,212-2 has been reported also in identified retinal bipolar cells [20] and in cerebral vascular smooth muscle cells [21]. In the latter case, WIN 55,212-2 and the endocannabinoid anandamide inhibited the LTCCs in a voltage-independent manner and the effects were PTX-sensitive. Despite these excellent agreements, however, other reports on the effects of cannabinoids on LTCCs appear controversial. In NG10815 cells [9] and in lactotroph-derived $\mathrm{GH}_{4} \mathrm{C}_{1}$ cell line [17], LTCCs are not affected by WIN 55,212-2 and cannabimimetic agonists up-regulate $\mathrm{Ca}^{2+}$ influxes through LTCCs in N18TG2 cells via a PTXinsensitive pathway [18].

\subsection{Role of the CB1R-mediated inhibition of LTCCs in hormone release and neuronal activity}

LTCCs play a critical role in the control of electrical activity and hormone release in GT1-7 neurons. Nimodipine is very effective in changing the shape of action potential and reducing the frequency, or even blocking, the spontaneous synchronized firing of GT1-7 neurons [28]. As the amount of intracellular $\mathrm{Ca}^{2+}$ inside a GT1-7 neuron is linearly related to the duration of spikes and depends on the frequency of bursting, LTCCs activity appears extremely critical in the control of GnRH release from GT1-7 cells. Several reports indicate that the pulsatile release of GnRH from GT1-7 and GT1-1 neuronal networks is largely controlled by LTCCs $[28,29,54]$ and only partially by R-type channels [31]. It is thus evident that inhibition of LTCCs by cannabimimetic agonists is expected to produce marked reductions of cell firing activity, lower $\mathrm{Ca}^{2+}$ entry and decreased release of GnRH from GT1-7 neurons. This is indeed what occurs when exogenous or endogenous cannabinoids are applied to GT1-7 neurons. These cells express sufficient densities of CB1Rs and possess the enzymes to produce and release endocannabinoids [27]. In this study, WIN 55,212-2 (20-50 $\mu \mathrm{M})$ was indeed very effective in reducing the $\mathrm{KCl}$-stimulated release of $\mathrm{GnRH}$ in GT1-7 neurons. Both, PTX and the CB1R antagonist AM-281 blocked this effect. As GnRH is the major regulator of reproduction in mammals [55], these findings suggest that exogenous cannabinoids administration may perturb reproduction through an inhibitory action on hypothalamic GnRH neurons [27].

We found of great interest that cannabimimetic agonists selectively inhibit the LTCCs controlling $\mathrm{Ca}^{2+}$-entry and GnRH release in GT1-7 neurons and that CB1R activation reduces the pulsatile release of GnRH from these cells [27]. The two effects are likely to be linked and this broadens the number of signal transduction pathways that might regulate the physiological and therapeutical effects of cannabinoids. $\mathrm{Ca}^{2+}$ channel inhibition by endocannabinoids is functional in the control of GABA and glutamate release at central synapses [15]. In addition, CB1Rs are among the most abundant $G$ protein-coupled receptors in the central nervous system and are preferentially located at the synaptic terminals [3]. Since endocannabinoids are synthesized and released postsynaptically during periods of intense neuronal activity, the presynaptic localization of CB1Rs suggests that these receptors might participate in a form of feedback inhibition by reducing the activity of presynaptic $\mathrm{Ca}^{2+}$ channels (N- and $\mathrm{P} / \mathrm{Q}-$ type). Following this scheme, endocannabinoids are shown to be implicated in various forms of synaptic plasticity [56].

Our findings add a new entry to the list of signal transduction pathways used by $\mathrm{CB} 1 \mathrm{R}$ to control $\mathrm{Ca}^{2+}$ influx in neurons and neuroendocrine cells that express LTCCs and CB1Rs. As LTCCs are mainly expressed in the soma and proximal dendrites of neurons and abundantly in neuroendocrine cells, their inhibition by CB1R most likely will alter somatic activities and hormone release. For instance, LTCCs activating at subthreshold potentials are expressed in midbrain dopaminergic neurons of substantia nigra [57] and hypothalamic suprachiasmatic nucleus neurons [58], which also express high densities of CB1R [59]. LTCCs regulate the shape of action potentials and the frequency of spontaneous firing [60], thus an effective up- or down-modulation of these channels by CB1R activation or deactivation can cause drastic changes to neuronal firing, neurotransmitter release and brain functions control. 


\section{Conclusions}

Our results suggest that the selective effects of CB1R agonists and inverse agonists on neuronal LTCCs may broaden our current understanding of the cannabinoids use in the treatment of several neurological diseases [61]. Neurons express different types of LTCCS $\left(\mathrm{Ca}_{\mathrm{v}} 1.2, \mathrm{Ca}_{\mathrm{v}} 1.3\right.$ and $\left.\mathrm{Ca}_{\mathrm{v}} 1.4\right)$ which regulate membrane excitability, action potential firing, intracellular signal transduction pathways, synaptic plasticity and synapse formation. Thus, it would not be surprising that some of the therapeutic effects of cannabinoids on central and peripheral neurons, such as analgesia, sedation, improvement of mood, stimulation of appetite, anti-emesis and neuroprotection, may derive directly or indirectly from the CB1Rinduced inhibition or potentiation of LTCCs.

\section{Acknowledgments}

This work was supported by the Marie Curie Research Training Network "CavNET" (contract no. MRTN-CT-2006-035367), the MIUR (grant COFIN no. 2005054435 to E.C.). H.H. was supported by an IMAGEEN project fellowship. We wish to thank Dr. Pamela Mellon (University of California, USA) for supplying the GT1-7 neurons.

\section{References}

[1] L.E. Hollister, Health aspects of cannabis, Pharmacol. Rev. 38 (1986) 1-20.

[2] R.G. Pertwee, The central neuropharmacology of psychotropic cannabinoids, Pharmacol. Ther. 36 (1988) 189-261.

[3] A. Ameri, The effects of cannabinoids on the brain, Progr. Neurobiol. 58 (1999) 315-348.

[4] A.C. Howlett, C.S. Breivogel, S.R. Childers, S.A. Deadwyler, R.E. Hampson, L.J. Porrino, Cannabinoid physiology and pharmacology: 30 years of progress, Neuropharmacology 47 (2004) 345-358.

[5] G. Demuth, A. Molleman, Cannabinoid signaling Life Sci. 78 (2006) 549-563.

[6] L.A. Matsuda, S.J. Lolait, M.J. Brownstein, A.C. Young, T.I. Bonner, Structure of a cannabinoid receptor and functional expression of the cloned cDNA, Nature 346 (1990) 561-564.

[7] A.C. Howlett, J.M. Qualy, L.L. Khachatrian, Involvement of $G_{i}$ in the inhibition of adenylate cyclase by cannabimimetic drugs, Mol. Pharmacol. 29 (1986) 307-313.

[8] M.P. Caulfield, D.A. Brown, Cannabinoid receptor agonists inhibit Ca currents in NG108-15 neuroblastoma cells via a pertussis-toxin sensitive mechanism, Br. J. Pharmacol. 106 (1992) 23l-232.

[9] K. Mackie, B. Hille, Cannabinoids inhibit N-type calcium channels in neuroblastoma-glioma cells, Proc. Natl. Acad. Sci. U.S.A. 89 (1992) 3825-3829.

[10] X.H. Pan, S.R. Ikeda, D.L. Lewis, Rat brain cannabinoid receptor modulates Ntype $\mathrm{Ca}^{2+}$ channels in a neuronal expression system, Mol. Pharmacol. 49(1996) 707-714.

[11] X.H. Pan, S.R. Ikeda, D.L. Lewis, SR $141716 \mathrm{~A}$ acts as an inverse agonist to increase neuronal voltage-dependent $\mathrm{Ca}^{2+}$ currents by reversal of tonic CB1 cannabinoid receptor activity, Mol. Pharmacol. 54 (1998) 1064-1072.

[12] S.A. Deadwyler, R.E. Hampson, B.A. Bennett, T.A. Edwards, J. Mu, M.A. Pacheco, S.J. Ward, S.R. Childers, Cannabinoids modulate potassium current in cultured hippocampal neurons, Recept. Channels 1 (1993) 121-134.

[13] K. Mackie, Y. Lai, R. Westenbroek, R. Mitchell, Cannabinoids activate an inwardly rectifying potassium conductance and inhibit Q-type calcium currents in AtT20 cells transfected with rat brain cannabinoid receptor, J. Neurosci. 15 (1995) 6552-6561.

[14] M. Bouaboula, C. Poinot-Chazel, B. Bourrie, X. Canat, B. Calandra, M. RinaldiCarmona, G. Le Fur, P. Casellas, Activation of mitogen-activated protein kinases by stimulation of the central cannabinoid receptor CB1, Biochem. J. 312 (1995) 637-641.

[15] K. Mackie, Cannabinoid receptors: where they are and what they do, J. Neuroendocr. 20 (2008) 10-14.

[16] S.A. Deadwyler, R.E. Hampson, J. Mu, A. Whyte, S. Childers, Cannabinoids modulate voltage sensitive potassium A-current in hippocampal neurons via a cAMP-dependent process, J. Pharmacol. Exp. Ther. 273 (1995) 734-743.

[17] B.Y. Ho, A. Stadnicka, P.L. Prather, A.R. Buckley, L.L. Current, Z.J. Bosnjak, W.M. Kwok, Cannabinoid CB1 receptor-mediated inhibition of prolactin release and signaling mechanisms in GH4C1 cells, Endocrinology 141 (2000) 1675-1685.

[18] V. Rubovitch, M. Gafni, Y. Sarn, The cannabinoid agonist DALN positively modulates L-type voltage dependent calcium-channels in N18TG2 neuroblastoma cells, Mol. Brain Res. 101 (2002) 93-102.

[19] A.J. Drysdale, D. Ryan, R.G. Pertwee, B. Platt, Cannabidiol-induced intracellular $\mathrm{Ca}^{2+}$ elevations in hippocampal cells, Neuropharmacology 50 (2006) 621-631.

[20] A. Straiker, N. Stella, D. Piomelli, K. Mackie, H.J. Karten, G. Maguire, Cannabinoid CB1 receptors and ligands in vertebrate retina: localization and function of an endogenous signaling system, Proc. Natl. Acad. Sci. U.S.A. 96 (1999) 14565-14570.
[21] D. Gebremedhin, A.R. Lange, W.B. Campbell, C.J. Hillard, D.R. Harder, Cannabinoid CB1 receptor of cat cerebral arterial muscle functions to inhibit L-type $\mathrm{Ca}^{2+}$ channel current, Am. J. Physiol. Heart Circ. Physiol. 276 (1999) 2085-2093.

[22] T. Endoh, Pharmacological characterization of inhibitory effects of postsynaptic opioid and cannabinoid receptors on calcium currents in neonatal rat nucleus tractus solitaries, Br. J. Pharmacol. 147 (2006) 391-401.

[23] J.M. Hernández-Guijo, V. Carabelli, L. Gandía, A.G. García, E. Carbone, Voltageindependent autocrine modulation of L-type channels mediated by ATP. opioids and catecholamines in rat chromaffin cells, Eur. J. Neurosci. 11 (1999) 3574-3584.

[24] P. Baldelli, J.M. Hernández-Guijo, V. Carabelli, M. Novara, T. Cesetti, E. AndrésMateos, C. Montiel, E. Carbone, Direct and remote modulation of L-channels in chromaffin cells: distinct actions on alpha1C and alpha1D subunits? Mol. Neurobiol. 29 (2004) 73-96.

[25] T. Cesetti, J.M. Hernandez-Guijo, P. Baldelli, V. Carabelli, E. Carbone, Opposite action of beta1- and beta2-adrenergic receptors on Cav1 L-channel current in rat adrenal chromaffin cells, J. Neurosci. 23 (2003) 73-83.

[26] P.L. Mellon, J.J. Windle, P.C. Goldsmith, C.A. Padula, J.L. Roberts, R.I. Weiner, Immortalization of hypothalamic GnRH neurons by genetically targeted tumorigenesis, Neuron 5 (1990) 1-10.

[27] C.M. Gammon, G.M. Freeman Jr., W. Xie, S.L. Petersen, W.C. Wetsel, Regulation of gonadotropin-releasing hormone secretion by cannabinoids, Endocrinology 146 (2005) 4491-4499.

[28] F. Van Goor, L.Z. Krsmanovic, K.J. Catt, S.S. Stojilkovic, Control of action potential-driven calcium influx in GT1 neurons by the activation status of sodium and calcium channels, Mol. Endocrinol. 13 (1999) 587-603.

[29] R. Vazquez-Martinez, S.L. Shorte, F.R. Boockfor, L.S. Frawley, Synchronized Exocytotic Bursts from gonadotropin-releasing hormone-expressing cells: dual control by intrinsic cellular pulsatility and gap junctional communication, Endocrinology 142 (2001) 2095-2101.

[30] G. Martínez de la Escalera, C. Clapp, Regulation of gonadotropin-releasing hormone secretion: insights from GT1 immortal GnRH neurons, Arch. Med. Res. 32 (2001) 486-498.

[31] M. Watanabe, Y. Sakuma, M. Kato, High expression of the R-type voltage-gated $\mathrm{Ca}^{2+}$ channel and its involvement in $\mathrm{Ca}^{2+}$-dependent gonadotropin-releasing hormone release in GT1-7 cells, Endocrinology 145 (2004) 2375-2383.

[32] A. Marcantoni, V. Carabelli, D.H. Vandael, V. Comunanza, E. Carbone, PDE type4 inhibition increases L-type $\mathrm{Ca}^{2+}$ currents, action potential firing, and quantal size of exocytosis in mouse chromaffin cells, Pflugers Arch. Eur. J. Physiol. 457 (2009) 1093-1110.

[33] M.M. Bosma, Ion channel properties and episodic activity in isolated immortalized gonadotropin-releasing hormone (GnRH) neurons, J. Membr. Biol. 136 (1993) 85-96.

[34] E. Carbone, H.D. Lux, A low voltage-activated, fully inactivating Ca channel in vertebrate sensory neurons, Nature 310 (1984) 501-502.

[35] A.C. Dolphin, Mechanisms of modulation of voltage-dependent calcium channels by $\mathrm{G}$ proteins, J. Physiol. 506 (1998) 3-11.

[36] J. Chemin, A. Monteil, E. Perez-Reyes, J. Nargeot, P. Lory, Direct inhibition of T-type calcium channels by the endogenous cannabinoid anandamid, EMBO J. 20 (2001) 7033-7040.

[37] H.R. Ross, I. Napier, M. Connor, Inhibition of recombinant human T-type calcium channels by $\Delta^{9}$-tetrahydrocannabinol and cannabidiol, J. Biol. Chem. 283 (2008) 16124-16134.

[38] W. Twitchell, S. Brown, K. Mackie, Cannabinoids inhibit N- and P/Q-type calcium channels in cultured rat hippocampal neurons, J. Neurophysiol. 78 (1997) $43-50$.

[39] S.P. Brown, P.K. Safo, W.G. Regehr, Endocannabinoids inhibit transmission at granule cell to purkinje cell synapses by modulating three types of presynaptic calcium channels, J. Neurosci. 24 (2004) 5623-5631.

[40] W.A. Catterall, E. Perez-Reyes, T.P. Snutch, J. Striessnig, International Union of Pharmacology. XLVIII. Nomenclature and structure-function relationships of voltage-gated calcium channels, Pharmacol. Rev. 57 (2005) 411-425.

[41] S.R. Ikeda, Voltage-dependent modulation of N-type calcium channels by Gprotein $\beta \gamma$ subunits, Nature 380 (1996) 255-258.

[42] C. Marchetti, E. Carbone, H.D. Lux, Effects of dopamine and noradrenaline on Ca channels of cultured sensory and sympathetic neurons of chick, Pflügers Arch. Eur. J. Physiol. 406 (1986) 104-111.

[43] B.P. Bean, Neurotransmitter inhibition of neuronal calcium currents by changes in channel voltage dependence, Nature 340 (1989) 153-156.

[44] V. Carabelli, M. Lovallo, V. Magnelli, H. Zucker, E. Carbone, Voltage-dependent modulation of single $\mathrm{N}$-type $\mathrm{Ca}^{2+}$ channel kinetics by receptor agonists in IMR32 cells, Biophys. J. 70 (1996) 2144-2154

[45] K.S. Elmslie, W. Zhou, S.W. Jones, LHRH and GTP- $\gamma$-S modify calcium current activation in bullfrog sympathetic, Neuron 5 (1990) 75-80.

[46] A. Fisyunov, V. Tsintsadze, R. Min, N. Burnashev, N. Lozovaya, Cannabinoids modulate the P-type high-voltage-activated calcium currents in Purkinje neurons, J. Neurophysiol. 96 (2006) 1267-1277.

[47] A. Marcantoni, P. Baldelli, J.M. Hernandez-Guijo, V. Comunanza, V. Carabelli, E. Carbone, L-type calcium channels in adrenal chromaffin cells: role in pacemaking and secretion, Cell Calcium 42 (2007) 397-408.

[48] H.C. Hartzell, P.F. Mery, R. Fischmeister, G. Szabo, Sympathetic regulation of cardiac calcium current is due exclusively to cAMP-dependent phosphorylation, Nature 351 (1991) 573-576.

[49] V. Carabelli, J.M. Hernández-Guijo, P. Baldelli, E. Carbone, Direct autocrine inhibition and cAMP-dependent potentiation of single L-type $\mathrm{Ca}^{2+}$ channels in bovine chromaffin cells, J. Physiol. 532 (2001) 73-90. 
[50] C. Ämmälä, F.M. Ashcroft, P. Rorsman, Cyclic AMP-dependent potentiation of exocytosis in insulin secreting pancreatic cells by stimulation of calciuminflux and direct interaction with the secretory machinery, Nature 363 (1993) 356-358.

[51] S.F. Oliveria, M.L. Dell'Acqua, W.A. Sather, AKAP79/150 anchoring of calcineurin controls neuronal L-type $\mathrm{Ca}^{2+}$ channel activity and nuclear signaling, Neuron 55 (2007) 261-275.

52] E. Carbone, V. Carabelli, T. Cesetti, P. Baldelli, J.M. Hernandez-Guijo, L. Giusta, G-protein- and cAMP-dependent L-channel gating modulation: a manifold system to control calcium entry in neurosecretory cells, Pflügers Arch. 442 (2001) 801-813.

[53] I. Calin-Jageman, A. Lee, Cav1 L-type $\mathrm{Ca}^{2+}$ channel signaling complexes in neurons, J. Neurochem. 105 (2008) 573-583.

[54] D.J. Spergel, L.Z. Krsmanovic, S.S. Stojilkovic, K.J. Catt, L-type $\mathrm{Ca}^{2+}$ channels mediate joint modulation by gamma-aminobutyric acid and glutamate of $\left[\mathrm{Ca}^{2+}\right]_{\mathrm{i}}$ and neuropeptide secretion in immortalized gonadodropin releasing hormone neurons, Neuroendocrinology 61 (1995) 499-508.
[55] V.H. Lee, L.T. Lee, B.K. Chow, Gonadotropin-releasing hormone: regulation of the GnRH gene, FEBS J. 275 (2008) 5458-5478.

[56] M.A. Diana, A. Marty, Endocannabinoid-mediated short-term synaptic plasticity: depolarization-induced suppression of inhibition (DSI) and depolarizationinduced suppression of excitation (DSE), Br. J. Pharmacol. 142 (2004) 9-19.

[57] S.C. Chan, J.N. Guzman, E. Ilijic, J.N. Mercer, C. Rick, T. Tkatch, G.E. Meredith, D.J. Surmeier, "Rejuvenation" protects neurons in mouse models of Parkinson's disease, Nature 447 (2007) 1081-1086.

[58] A.C. Jackson, G.L. Yao, B.P. Bean, Mechanism of spontaneous firing in dorsomedial suprachiasmatic nucleus neurons, J. Neurosci. 24 (2004) 7985-7998.

[59] C.R. Lupica, A.C. Riegel, Endocannabinoid release from midbrain dopamine neurons: a potential substrate for cannabinoid receptor antagonist treatment of addiction, Neuropharmacology 48 (2005) 1105-1116.

[60] B.P. Bean, The action potential in mammalian central neurons, Nat. Rev. 8(2007) 451-465.

[61] R. Mechoulam, E. Shohami, Endocannabinoids and traumatic brain injury, Mol. Neurobiol. 36 (2007) 68-74. 